\title{
DTA Determination of Phase Equilibria in the Ternary Ag-Sb-Sn System
}

\author{
Joanna Lapsa ${ }^{1} \cdot$ Bogusław Onderka ${ }^{1}$
}

Submitted: 31 July 2018/in revised form: 28 October 2018/Published online: 21 November 2018

(C) The Author(s) 2018

\begin{abstract}
The experimental data on phase transitions temperatures in $\mathrm{Ag}-\mathrm{Sb}-\mathrm{Sn}$ system have been obtained by DTA technique during heating and cooling cycles. To verify phase equilibria in this system, a number of 19 different samples were studied in the temperature range $100-850{ }^{\circ} \mathrm{C}$. The existence of coexisting phases and their composition was analysed by SEM and EDX techniques for 5 distinct samples after their thermal equilibration at $400{ }^{\circ} \mathrm{C}$. The obtained data were compared with isopleths calculated from available literature assessments.
\end{abstract}

Keywords isothermal equilibration · metals and alloys . phase diagrams $\cdot$ thermal analysis

\section{Introduction}

The pressure from EU legislature to prohibit the use of lead containing solders stimulated the search for new, lead-free materials. Two subsequent COST Actions, 531 and MP0602, selected a number of alloys which can be used as a substitute for traditional $\mathrm{Pb}-\mathrm{Sn}$ solder. One of them, (Ag$\mathrm{Sn}$ alloy) was found to be a suitable material, however

This invited article is part of a special issue of the Journal of Phase Equilibria and Diffusion in honor of Prof. Jan Vrestal's 80th birthday. This special issue was organized by Prof. Andrew Watson, Coventry University, and Dr. Ales Kroupa, Institute of Physics of Materials, Brno, Czech Republic.

Bogusław Onderka

onderka@agh.edu.pl

1 Department of Non-Ferrous Metals, AGH University of Science and Technology, 30 Mickiewicza Avenue, 30-059 Kraków, Poland additional elements were needed to suppress its coarsening. Lee et al. ${ }^{[1,2]}$ investigated the influence of $\mathrm{Sb}$ addition into Sn-matrix on the microstructure, adhesive strength and fatigue of $\mathrm{Ag}-\mathrm{Sb}-\mathrm{Sn}$ alloys working as solder joints. They found that the addition of antimony causes solid solution hardening and depresses the growth of the interfacial intermetallic compound layers. It also improves adhesive strength and thermal resistance of Sn35Ag alloy. The investigation of the influence of $\mathrm{Sb}$ content on reliability of $\mathrm{SnAgSb}$ solder showed that fatigue life of the joints increases with the amount of $\mathrm{Sb}$ added. Consequently, the $\mathrm{Ag}-\mathrm{Sb}-\mathrm{Sn}$ system attracted the attention as the one being chosen for a new lead-free solder material.

Needless to say, phase relations in this system, especially in the concentration range close to binary Ag-Sn eutectic, became an object of great interest. Masson and Kirkpatrick $^{[3]}$ investigated liquidus surface and identified invariant reactions using DTA and microprobe analysis. They presented liquidus projection and determined composition of co-existing phases for the two invariant reactions.

Further studies of phase equilibria in Ag-Sb-Sn system were conducted by Oberndorff et al., ${ }^{[4]}$ who constructed an isothermal cross-section through the ternary system at $220{ }^{\circ} \mathrm{C}$. They used diffusion couples and analysis of equilibrated alloys. This work showed that SbSn compound is not present in the equilibrium phase at this temperature. They identified also solid solution between intermetallic phases labeled $\zeta$-phase. For the phase notation and structure see Table 1.

In their Materials Science International Team (MSIT) publication (http://www.msiport.com/), Schmid-Fetzer et al. ${ }^{[5]}$ reviewed the existing literature data for constituent binaries and ternary Ag-Sb-Sn. 
Table 1 Phases in the Ag-SbSn ternary system ${ }^{[11]}$

\begin{tabular}{lccl}
\hline Phase & Strukturbericht designation & Pearson symbol & Prototypes \\
\hline Liquid & $\ldots$ & $\ldots$ & $\ldots$ \\
$(\mathrm{Ag})$ & $\mathrm{A} 1$ & $c F 4$ & $\mathrm{Cu}$ \\
$(\mathrm{Sb})$ & $\mathrm{A} 7$ & $h R 2$ & $\alpha$-As \\
$\beta \mathrm{Sn}$ & $\mathrm{A} 5$ & $t I 4$ & $\beta$-Sn \\
$\alpha \mathrm{Sn}$ & $\mathrm{A} 4$ & $c F 8$ & $\mathrm{C}$ (diamond) \\
$\mathrm{SbSn}$ & $\mathrm{B} 1$ & $c F 8$ & $\mathrm{NaCl}$ \\
$\mathrm{Sb}_{2} \mathrm{Sn}_{3}$ & $\ldots$ & $\ldots$ & $\ldots$ \\
$\zeta-\mathrm{hcp}$ & $\mathrm{A} 3$ & $h P 2$ & $\mathrm{Mg}(\mathrm{hcp})$ \\
$\varepsilon$ & $\mathrm{L} 6_{0}$ & $t P 4$ & $\mathrm{Cu} \mathrm{Ti}_{3}$ \\
\hline
\end{tabular}

More extensive studies on ternary Ag-Sb-Sn phase diagram were conducted almost in the same time by Lin et al. ${ }^{[6]}$ and Lee et al. ${ }^{[7]}$ They investigated isothermal sections of the ternary system at 150,260 and $400{ }^{\circ} \mathrm{C}$, respectively. These studies confirmed that there is a mutual solid solubility between $\mathrm{Ag}_{3} \mathrm{Sn}$ and $\mathrm{Ag}_{3} \mathrm{Sb}$ intermetallic phases ( $\varepsilon$ phase) as well as between $\mathrm{Ag}_{4} \mathrm{Sn}$ and $\mathrm{Ag}_{4} \mathrm{Sb}$ phases ( $\zeta$ phase). Equilibrium phases found in this temperature range are very similar to one another. Moreover, Lee et al. ${ }^{[7]}$ investigated also interfacial reactions between $\mathrm{Sb}-\mathrm{Sn}$ alloy and Ag substrate.

Following previous works Chen et al. ${ }^{[8]}$ determined experimentally an isothermal section at $250{ }^{\circ} \mathrm{C}$ and liquidus projection of the ternary $\mathrm{Ag}-\mathrm{Sb}-\mathrm{Sn}$ system. They found three tie-triangles: $\mathrm{L}+\mathrm{Sb}_{2} \mathrm{Sn}_{3}+\varepsilon, \quad \mathrm{Sb}_{2} \mathrm{Sn}_{3-}$ $+\mathrm{SbSn}+\varepsilon$ and $\mathrm{SbSn}+(\mathrm{Sb})+\varepsilon$. They also identified three ternary invariant reactions at 379,314 and $233{ }^{\circ} \mathrm{C}$, respectively. Chen et al. ${ }^{[8]}$ concluded that $\zeta-\mathrm{Ag}_{5} \mathrm{Sn}$ and $\zeta$ $\mathrm{Ag}_{17} \mathrm{Sb}_{3}$ phases form continuous solid solution.

However, temperatures of these invariant reactions are different from the calculated results by $\mathrm{Oh}$ et al. ${ }^{[9]}$ The biggest difference is in four-phase equilibrium $\mathrm{L}+\mathrm{SbSn} \leftrightarrow \mathrm{Sb}_{2} \mathrm{Sn}_{3}+\varepsilon$, which differs from $\mathrm{L}+\varepsilon+\mathrm{SbSn} \leftrightarrow \mathrm{Sb}_{2} \mathrm{Sn}_{3}$ equilibrium suggested by $\mathrm{Oh}$ et al. ${ }^{[9]}$ Calculations of $\mathrm{Oh}$ et al. ${ }^{[9]}$ were based on the liquidus projection given by Masson and Kirkpatric, ${ }^{[3]}$ who did not report $\mathrm{SbSn} / \mathrm{Sb}_{2} \mathrm{Sn}_{3}$ boundary and also did not detect $\mathrm{Sb}_{2} \mathrm{Sn}_{3}$ phase. It was the beginning of the discrepancy between different visions of this Sn-rich corner of the ternary system, which results from the accepted constitution of Sb-Sn binary system.

In parallel to the studies of experimental surface tension and density of Sn-3.8 at.\% Ag eutectic base liquid alloys (with $0.03,0.06$ and 0.09 molar fraction of $\mathrm{Sb}$ ) at a temperature range from 550 to $1200 \mathrm{~K}$, Moser et al., ${ }^{[10]}$ performed solidification simulation and analysed the change of the terminating temperatures of solidification process. Moreover, they performed experimental determination of phase diagram and optimization of thermodynamic model parameters of phases in the Ag-Sb-Sn system by the DSC and thermal equilibration method.

Since the new solder may be located at Sn-rich corner of the system, it was important to resolve this problem due to the uncertainty of the solidification temperature. Consequently, Gierlotka et al. ${ }^{[11]}$ recalculated ternary system and reported three class II ternary invariant reactions: $\mathrm{L}+(\mathrm{Sb}) \leftrightarrow \varepsilon+\mathrm{SbSn}, \quad \mathrm{L}+\mathrm{SbSn} \leftrightarrow \mathrm{Sb}_{2} \mathrm{Sn}_{3}+\varepsilon \quad$ and $\mathrm{L}+\mathrm{Sb}_{2} \mathrm{Sn}_{3} \leftrightarrow \beta \mathrm{Sn}+\varepsilon$, which take place at 379,313 and $231{ }^{\circ} \mathrm{C}$, respectively. However, the range of the stability of $\mathrm{Sn}_{3} \mathrm{Sb}_{2}$ phase is still not certain. In their model, the $\mathrm{Sn}_{3} \mathrm{Sb}_{2}$ phase is stable down to room temperature. They modelled continuous solid solution $\zeta$ (hcp_A3) as a substiutional solution.

The problem returned with the study of $\mathrm{Li}$ et al. ${ }^{[12]}$ who studied this ternary system calorimetrically and by DSC method to identify the temperature of the invariant reactions and to suggest the reactions scheme. In this work authors claim that $\mathrm{Sn}_{3} \mathrm{Sb}_{2}$ phase is not stable at low temperature, and they proposed one more invariant reaction $\mathrm{Sb}_{2} \mathrm{Sn}_{3} \leftrightarrow \varepsilon+\mathrm{SbSn}+\beta$-Sn below $211{ }^{\circ} \mathrm{C}$ (Table 5).

The problems with the description of the part of low temperature equilibria will be even more difficult, since in their recent paper Schmetterer et al. ${ }^{[13]}$ suggested that $\mathrm{Sb}_{2} \mathrm{Sn}_{3}$ phase does not exist at all. Instead, there is a $\mathrm{Sb}_{3} \mathrm{Sn}_{4}$ phase present in the binary Sb-Sn system. However, there is still an open question if this observed phase is an independent compound.

As far as thermodynamic properties of $\mathrm{Ag}-\mathrm{Sb}-\mathrm{Sn}$ liquid solutions are concerned, the situation is much more clear. This system was investigated calorimetrically by Gather et al. ${ }^{[15]}$ and Li et al. ${ }^{[12]}$ Their results agree well at $950{ }^{\circ} \mathrm{C}$ across the whole composition range. Recently, Łapsa and Onderka $^{[14]}$ published the paper in which except for the heat of mixing data, activities of tin in liquid phase were reported. They were measured with the e.m.f cell with the solid electrolyte. Papers ${ }^{[12,14,15]}$ provide complete description of the liquid phase in this ternary system.

From the above brief literature survey one can conclude that while the liquid phase has been thoroughly 
investigated, the relation between solid phases still can be questioned. Therefore, it was decided to enlarge this kind of information and to conduct further studies of phase relations in this ternary system by using DTA experiments.

\section{Experimental}

The ternary alloy samples were prepared from pieces of pure elements: Ag (99.99\%, Aldrich, USA), Sn (99.99\%, POCh, Poland) and $\mathrm{Sb}(>99.5 \%$, Fluka AG, Switzerland). After melting in evacuated quartz capsules at $800{ }^{\circ} \mathrm{C}$, all samples were held at $300^{\circ} \mathrm{C}$ for 15 days to obtain thermodynamic equilibrium. After equilibration, specimens were quenched in iced water and sealed again under vacuum in self-made quartz crucibles. The total weight of the samples used for the thermal analysis experiments was about $250 \mathrm{mg}$.

Liquidus temperatures and phase transformation temperatures were determined by differential thermal analysis (DTA), which was carried out in an atmosphere of flowing argon. Samples for DTA investigations were chosen along five cross-sections of the ternary phase diagram: $x_{\mathrm{Sn}} / x_{\mathrm{Ag}-}$ $=0.4286, \quad x_{\mathrm{Sn}} / x_{\mathrm{Ag}}=2.333, \quad x_{\mathrm{Sn}} / x_{\mathrm{Sb}}=2.333, x_{\mathrm{Ag}} / x_{\mathrm{Sb}}=1$ and $x_{\mathrm{Sn}}=0.2$. The composition of studied 19 samples is shown in Fig. 1. The measurements of selected samples were performed on DTA/DSC (differential scanning calorimetry) 404 F1 Pegasus NETZSCH (Germany) apparatus in the temperature range from 100 to $850{ }^{\circ} \mathrm{C}$. The DTA instrument consists of a single furnace and a

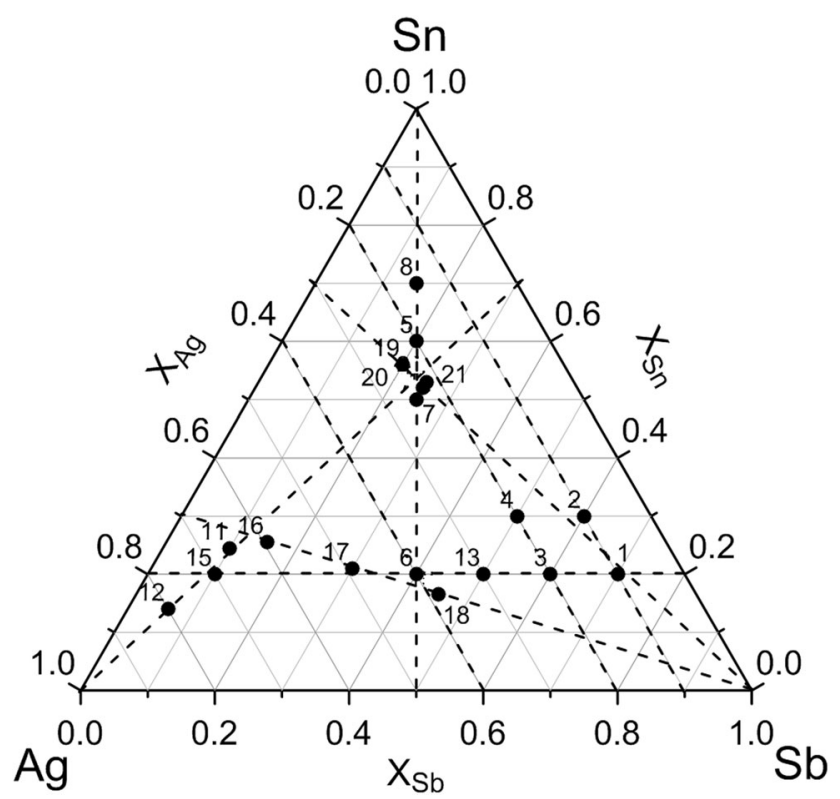

Fig. 1 The compositions of studied samples symmetrical sample carrier with positions for the sample and the reference. A sketch of quartz DTA crucible containing the sample is shown in Fig. 2. The empty sealed quartz DTA crucible was adopted as a reference. Calibration was done using the melting points of the high purity metals, $\mathrm{In}, \mathrm{Sn}, \mathrm{Pb}, \mathrm{Zn}, \mathrm{Al}$, and $\mathrm{Au}$ to establish an internal calibration file. The calibrating samples were also sealed under vacuum in quartz crucibles.

The total experimental error of the method has been estimated to be $\pm 2{ }^{\circ} \mathrm{C}$. Generally, two heating and cooling cycles were recorded for each sample. The minimum temperature between the cycles was $60^{\circ} \mathrm{C}$ in order to allow for possible supercooling. The heating/cooling rate was $5 \%$ min for both cycles. Additionally, to check the reliability of this rate, the DTA curves at 1 and $10 \% \mathrm{~min}$ were recorded for some samples. Liquidus temperatures on heating were evaluated from the peak maximum while those on cooling from the corresponding endset. An example of DTA heating cycles at 1,5 and $10 \% \mathrm{~min}$ scanning rate is shown in Fig. 3. Although it was demonstrated by Boettinger et al. ${ }^{[16]}$ that for multi-component alloys the peak maximum may (depending on a number of parameters, including the heating rate) yield temperature values somewhat higher than the true liquidus temperature, this evaluation is still considered a very good approximation, especially with heating rates of $5 \% \mathrm{~min}$ or less. The heating rate of $1 \% \mathrm{~min}$ allows to separate the signal features as is shown in Fig. 3 in temperature range from 300 to $350{ }^{\circ} \mathrm{C}$.

Besides thermal analysis, isothermal equilibration studies were also conducted. After sealing samples under vacuum, ternary alloys after pre-melting at $800{ }^{\circ} \mathrm{C}$ were kept at constant temperature $400{ }^{\circ} \mathrm{C}$ for 30 days, and at $300{ }^{\circ} \mathrm{C}$ for 60 days. After quenching in iced water they

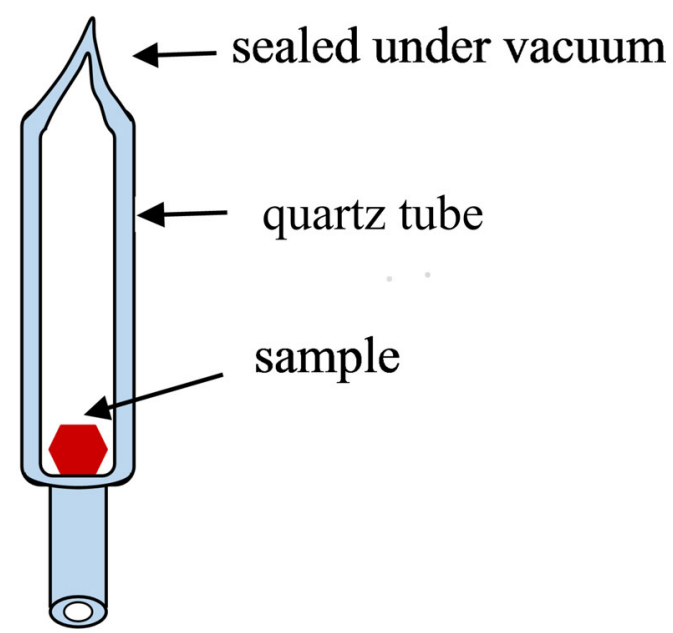

Fig. 2 A sketch of the self-made quartz DTA crucible 
were examined by metallographic and Electron Probe Microanalysis (EPMA) analysis. For quantitative EPMA results, the samples were analysed using an acceleration voltage of $20 \mathrm{kV}$ with cobalt as calibration standard for the beam current, gain and resolution of the spectrometer. The $\mathrm{X}$-ray intensities were corrected for $\mathrm{Z}$ Absorption Fluorescence (ZAF) effects using pure elements as standards. Microanalysis (EPMA) was used to check the overall composition of the samples, the uniformity of chemical composition, and the composition of the coexisting phases.

\section{Results}

Subsequent Fig. 4, 5, 6, and 7 show results obtained from DTA measurements for the total of 19 samples located in the respective four cross-sections (isopleths) investigated in this study. The experimental results are also collected in Tables 2, 3 and 4 together with the initial compositions. The coherence with other thermal analysis data were observed, especially, comparing our own data with the results of calculation of: Oh et al. ${ }^{[9]}$-Fig. 4 and 6 and Gierlotka et al. ${ }^{[1]}$ - Fig. 5 and 7 . In the terminal left figure the phase fields were described for the phase diagram calculated from parameters assessed by Moser et al. ${ }^{[10]}$
Fig. 3 Example of DTA heating cycles at 1,5 and $10 \%$ min scanning rate of sample s.5 of composition $\mathrm{Ag}_{0.2} \mathrm{Sb}_{0.2} \mathrm{Sn}_{0.6}$

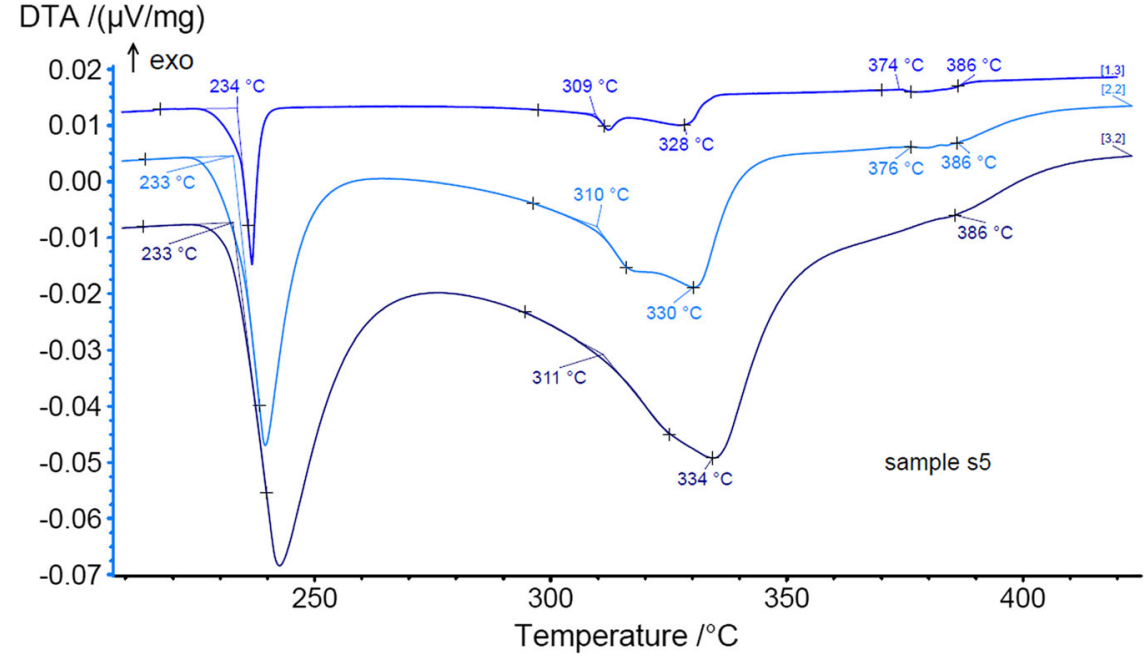

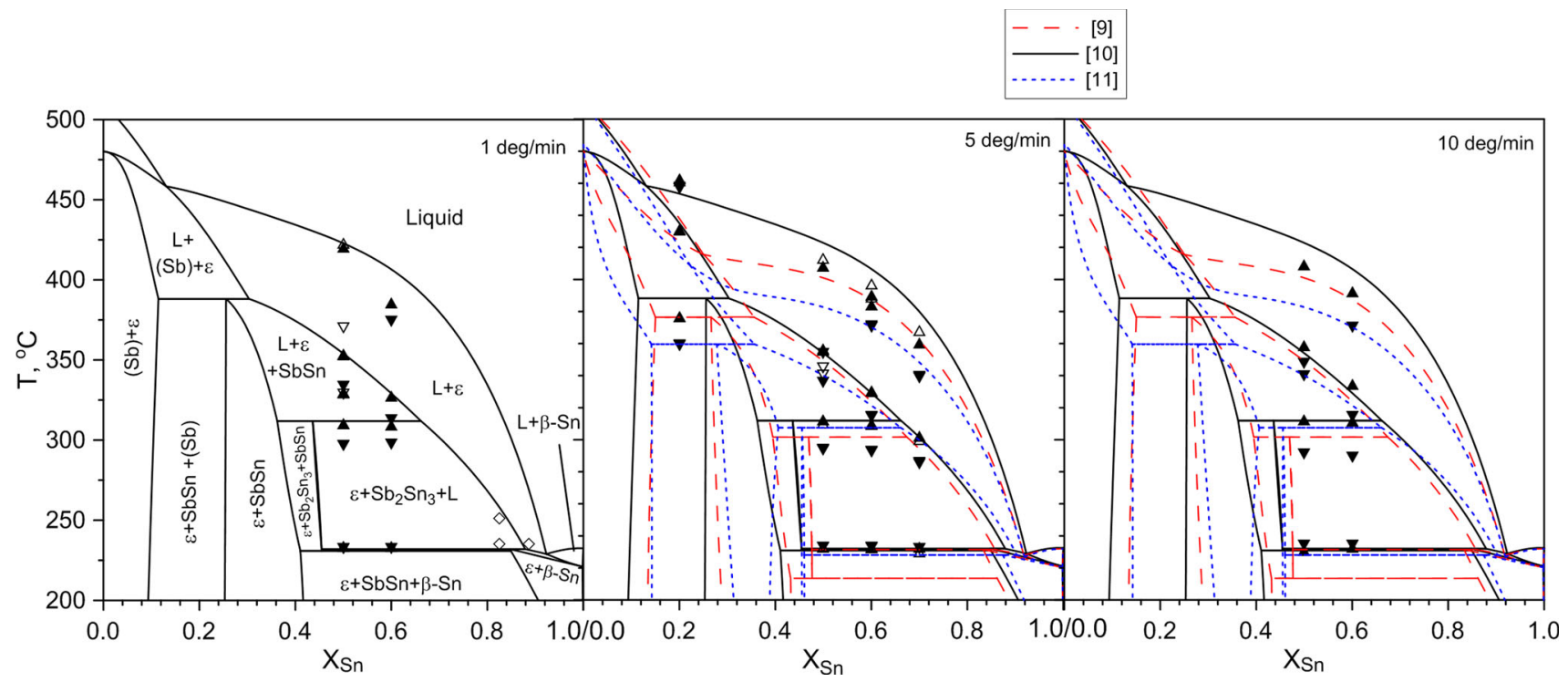

Fig. 4 Experimental data compared with calculated for the $x_{\mathrm{Ag}} /$ $x_{\mathrm{Sb}}=1$ section of Ag-Sb-Sn system of Ref 9-11. The data of Masson et al. ${ }^{[3]}$ were superimposed: diamond symbols description: filled triangle $-\mathrm{h} 1$, open triangle $-\mathrm{h} 2$, inverted filled triangle $-\mathrm{c} 1$, inverted open triangle $-\mathrm{c} 2$ (Tables 2,3 , and 4$)$ 


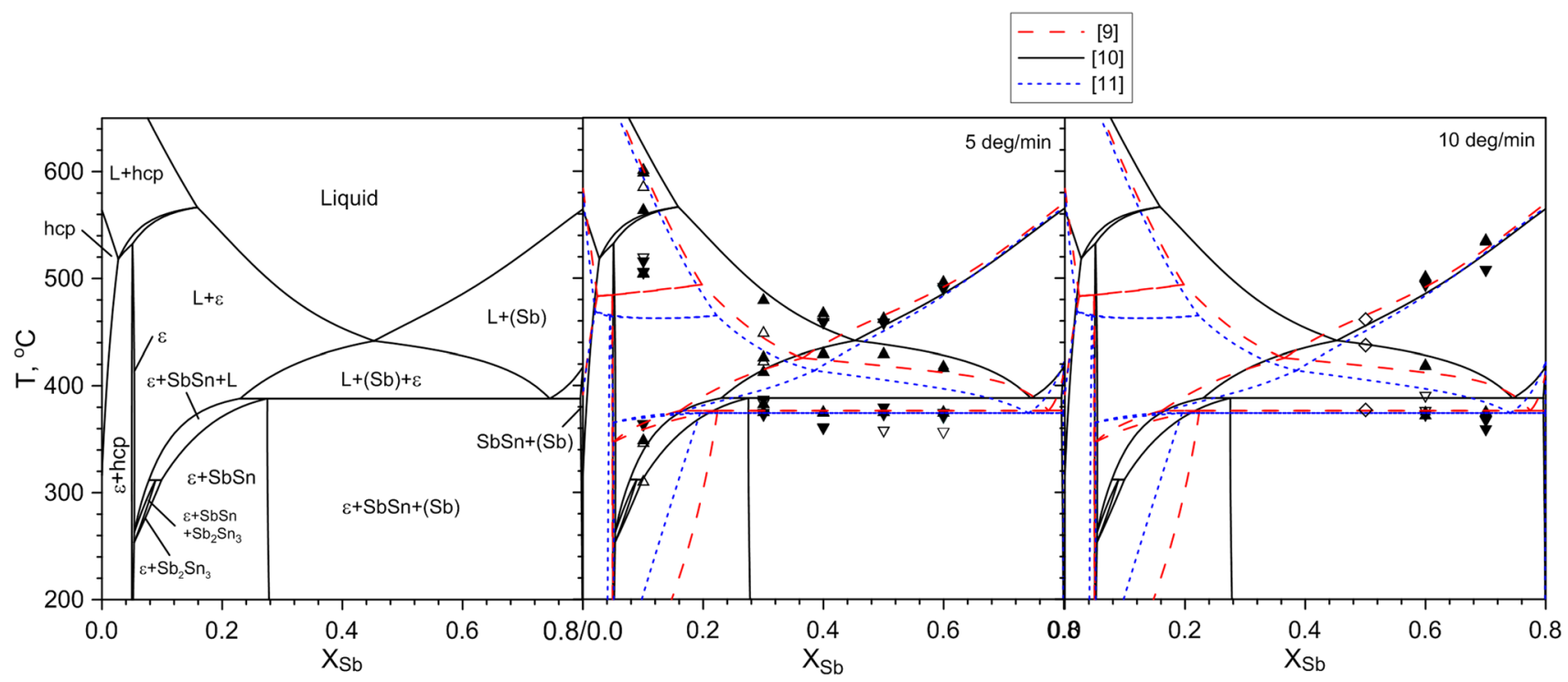

Fig. 5 Experimental data compared with calculated for the section $x_{\mathrm{Sn}}=0.2$ of $\mathrm{Ag}-\mathrm{Sb}-\mathrm{Sn}$ system from assessments. ${ }^{[9-11]}$ The experimental data of Moser et al. ${ }^{[10]}$ were superimposed: diamond symbols

description: filled triangle $-\mathrm{h} 1$, open triangle $-\mathrm{h} 2$, inverted filled triangle $-\mathrm{c} 1$, inverted open triangle $-\mathrm{c} 2$ (Tables 2,3 , and 4)

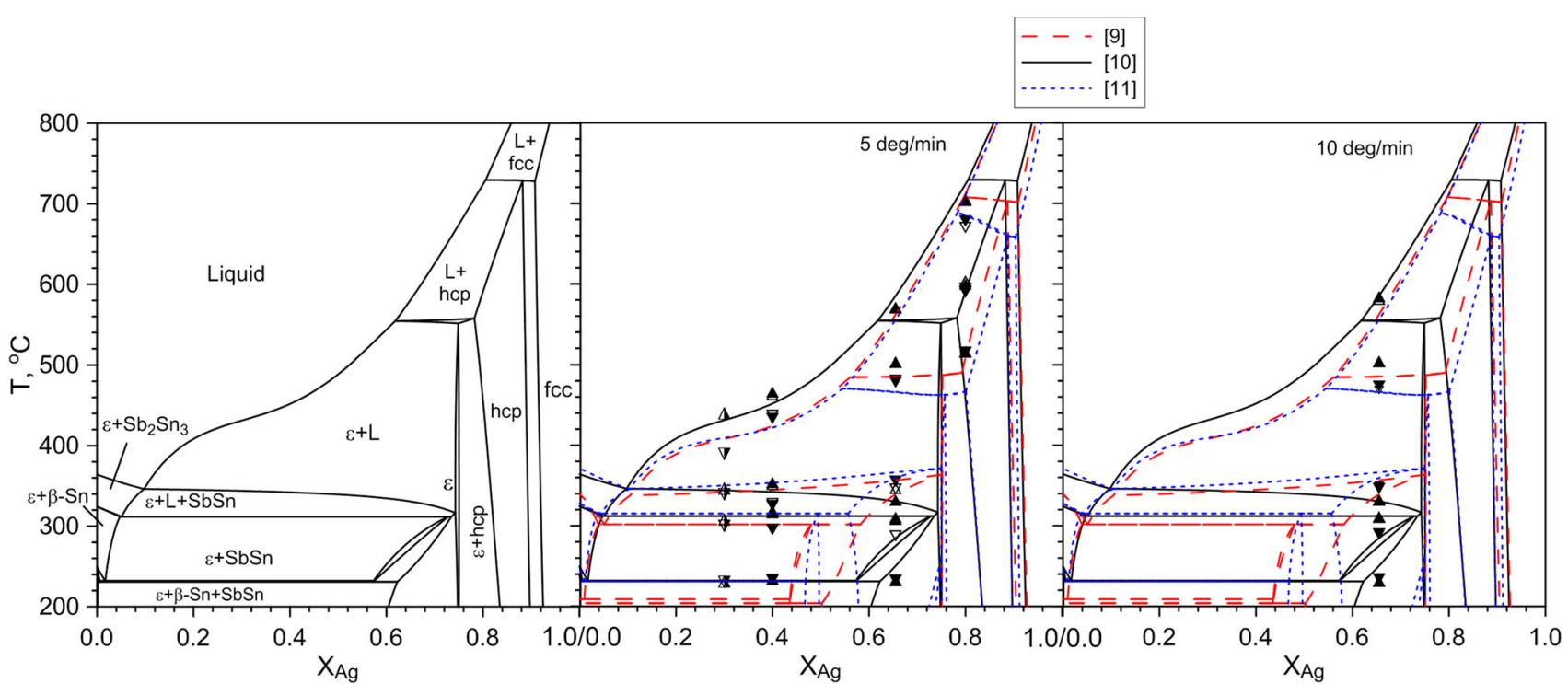

Fig. 6 Experimental data compared with the Ag-Sb-Sn system section at $x_{\mathrm{Sn}} / x_{\mathrm{Sb}}=2.333$ calculated from Ref 9-11. The experimental data of $\mathrm{Li}$ et al. ${ }^{[12]}$ detected at $1 \% \mathrm{~min}$ were superimposed: partial open filled triangle-heating and partial inverted open filled

(black solid line). For diagram clarity in this phase diagram other assessments were not enclosed.

For all samples of compositions located in Sn rich range the detected temperature of liquidus is close to the liquidus surface calculated from Oh's assessment ${ }^{[9]}$ regardless of the heating rate (Fig. 4).

The temperature of $U_{3}$ reaction obtained in this work agrees in the range of experimental error with other triangle-cooling. Symbols description: filled triangle- $\mathrm{h} 1$, open triangle $-\mathrm{h} 2$, inverted filled triangle $-\mathrm{c} 1$, inverted open triangle $-\mathrm{c} 2$ (Tables 2, 3, and 4)

experimental data as well as with the results of model calculations $^{[9-11]}$ (Fig. 4 and 6).

The same conclusion can be drawn for the temperature of reaction $\mathrm{U}_{2}$, but the significant undercooling was observed during cooling cycles (Fig. 4 and 5). While the experimental temperature of reaction $U_{1}$ is similar to that calculated from assessments of $\mathrm{Oh}$ et al. ${ }^{[9]}$ and Gierlotka et al., ${ }^{[11]}$ it differs more than $3 \%$ from the calculated value of Moser et al. ${ }^{[10]}$ (Fig. 4, 5 and 7). 


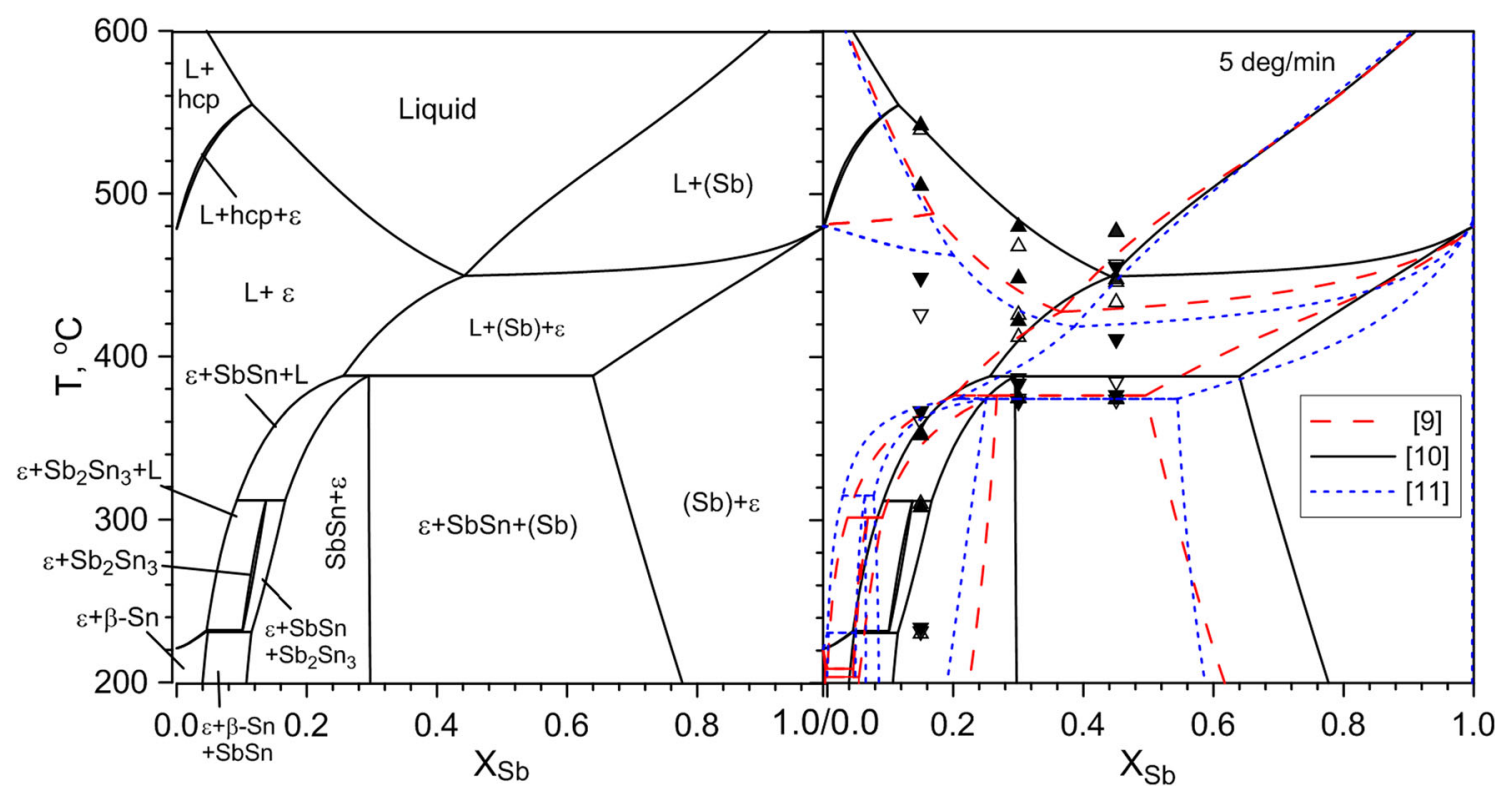

Fig. 7 DTA data obtained in present work shown on the Ag-Sb-Sn system section at $x_{\mathrm{Sn}} / x_{\mathrm{Ag}}=0.4286$ calculated from Ref 9-11. Symbols description: filled triangle $-\mathrm{h} 1$, open triangle $-\mathrm{h} 2$, inverted filled triangle $-\mathrm{c} 1$, inverted open triangle $-\mathrm{c} 2($ Tables 2,3 , and 4$)$

Figure 5 shows that antimony-rich liquidus for $x_{\mathrm{Sn}}=0.2$ diagram section is consistent with all assessments. ${ }^{[9-11]}$ In turn, in case of $x_{\mathrm{Sn}} / x_{\mathrm{Ag}}=0.4286$ section, the liquidus temperatures (Table 2) agree well with calculated data of Moser et al. ${ }^{[10]}$ (Fig. 7).

The difference of $2^{\circ}-3^{\circ}$ can be observed between DTA results obtained for invariant reactions at the rate $10 \% \mathrm{~min}$ for sample s11 $\left(\mathrm{Ag}_{0.65} \mathrm{Sb}_{0.105} \mathrm{Sn}_{0.245}\right)$ and sample (55) (Sn30 at. pct, $\mathrm{Sb}-10$ at. pct, $\mathrm{Ag})^{[8]}: 230.9 / 233.0$ and $310.9 /$ 314.0 , respectively. It should be noted that in the paper of Chen et al., ${ }^{[8]}$ for all reactions the temperatures were determined from peaks not from the onset which can generate overestimation of the temperature of invariant reactions.

Similarly, comparing DTA results for invariant reaction at the rate $1 \%$ min obtained for samples s1-2 $\left(\mathrm{Ag}_{0.1} \mathrm{Sb}_{0.7}\right.$ $\mathrm{Sn}_{0.2}$ and $\mathrm{Ag}_{0.1} \mathrm{Sb}_{0.6} \mathrm{Sn}_{0.3}$ ) and sample (13) (Sn-15 at. pct, Sb-684 at. pct, $\mathrm{Ag})^{[3]}\left(1.5^{\circ} / \mathrm{min}\right)$, the difference of $2.5^{\circ}$ can be observed: 377 and $379.5{ }^{\circ} \mathrm{C}$, respectively.

A typical DTA curves of one heating cycle obtained with rates 1,5 and $10 \%$ min for sample s.5 $\left(\mathrm{Ag}_{0.2} \mathrm{Sb}_{0.2-}\right.$ $\left.\mathrm{Sn}_{0.6}\right)$ are shown as an example in Fig. 3. It demonstrates that rates lower than standard $10 \% \mathrm{~min}$ are more appropriate in the DTA experiments in this system to determine an onset temperature from the thermal signals.

Generally, during cooling cycles performed at the rate $5 \%$ min, a significant liquidus undercooling of $20-50{ }^{\circ} \mathrm{C}$ was observed for almost all samples (Table 2) and even about $100{ }^{\circ} \mathrm{C}$ in the samples s.15-17.

The difference of the thermal signals of first and second cycle was observed in some samples (Table 2, s.3, 11, 15,
$17,18)$ which is the evidence of the retardation of phase precipitation during cooling with $5 \% \mathrm{~min}$ rate.

Additionally, the thermal feature of $328-330{ }^{\circ} \mathrm{C}$ was detected as a signal peak in $1 \% \mathrm{~min}$ rate cycle of samples s.5 and s. 7. Such result is close to the invariant reaction $\mathrm{P} 1: \mathrm{L}+\varepsilon+\mathrm{SbSn} \leftrightarrow \mathrm{Sb}_{2} \mathrm{Sn}_{3}$ at $328.9{ }^{\circ} \mathrm{C}$ calculated from the assessment of Oh et al. ${ }^{[9]}$ It seems that the answer of the reactions in the ternary system gives us a construction of reliable binary $\mathrm{Sb}$-Sn phase diagram, ${ }^{[13]}$ especially the analysis of the $\mathrm{Sb}_{2} \mathrm{Sn}_{3}$ compound stability range.

The comparison of invariant reaction temperatures determined by experimental and assessment methods in $\mathrm{Ag}-\mathrm{Sb}-\mathrm{Sn}$ system is shown in Table 5.

The determination of phase constituents at the end of tie-lines and composition of coexisting phases of 5 samples was done by SEM and EDX techniques after their thermal equilibration at $400{ }^{\circ} \mathrm{C}$ during 30 days. The examples of micrographs of equilibrated samples $(0.74 \mathrm{Ag}-0.134 \mathrm{Sb}$ $0.126 \mathrm{Sn}$ and $0.74 \mathrm{Ag}-0.082 \mathrm{Sb}-0.178 \mathrm{Sn}$ ) are shown in Fig. 8. The initial and final compositions are shown in Table 6. The results obtained in temperature $400{ }^{\circ} \mathrm{C}$ are very similar to the results of Lin et al. ${ }^{[6]}$ investigation of the isothermal section of the ternary system at the same temperature. First three samples (1, 2, 3, Table 6) show equilibration results as the one detected in sample (20) $0.1 \mathrm{Ag} 0.85 \mathrm{Sb} 0.05 \mathrm{Sn}$ of ${ }^{[6]}$ in which also two-phase equilibrium $\varepsilon+(\mathrm{Sb})$ has been determined (Fig. 8a). The initial composition of equilibrated samples (1-4) was chosen close to the stability limit of $\varepsilon$ phase. So at BSE microphotographs in Fig. 8(a) and (b) the precipitation of second 
Table 2 Heating and cooling features recorded during two temperature cycles with $5 \% \mathrm{~min}$
Sample composition (sample no.)

$\mathrm{Ag}_{0.1} \mathrm{Sb}_{0.7} \mathrm{Sn}_{0.2}$ (s.1)

$\mathrm{Ag}_{0.2} \mathrm{Sb}_{0.6} \mathrm{Sn}_{0.2}$ (s.3)

$\mathrm{Ag}_{0.2} \mathrm{Sb}_{0.5} \mathrm{Sn}_{0.3}(\mathrm{~s} .4)$

$\mathrm{Ag}_{0.2} \mathrm{Sb}_{0.2} \mathrm{Sn}_{0.6}$ (s.5)

$\mathrm{Ag}_{0.25} \mathrm{Sb}_{0.25} \mathrm{Sn}_{0.5}$ (s.7)

$\mathrm{Ag}_{0.15} \mathrm{Sb}_{0.15} \mathrm{Sn}_{0.7}(\mathrm{~s} .8)$

$\mathrm{Ag}_{0.4} \mathrm{Sb}_{0.18} \mathrm{Sn}_{0.42}$ (s.10)

$\mathrm{Ag}_{0.65} \mathrm{Sb}_{0.105} \mathrm{Sn}_{0.245}$ (s.11)

$\mathrm{Ag}_{0.8} \mathrm{Sb}_{0.06} \mathrm{Sn}_{0.14}(\mathrm{~s} .12)$

$\mathrm{Ag}_{0.3} \mathrm{Sb}_{0.5} \mathrm{Sn}_{0.2}(\mathrm{s.13})$

$\mathrm{Ag}_{0.7} \mathrm{Sb}_{0.1} \mathrm{Sn}_{0.2}(\mathrm{~s} .15)$
Cycle (a)

Thermal signals

Heating (b) and cooling (c) features, ${ }^{\circ} \mathrm{C}$

377 o, $535 \mathrm{p}$

$377 \mathrm{o}, 534 \mathrm{p}$

$357,366,498$

$357.3,365.7,501$

376 o, 418 p, 498 p

376 o, 418 p, 497 p

$369,373,488$

355,490

357 o, 376 o, 402 p, 462 p

356 o, 375 o, 400 p, 463 p

$360,361,442$

$361,363,448$

233 o, 310 o, 330 p, 376 o, 386 p

233 o, 310 o, 330 p, 389 p, 397 p

233, 292, 314, 370

233, 293, 314, 371

376 o, $431 \mathrm{p}, 469 \mathrm{p}$

377 o, 431 p, 465 p

359,457

359,457

233 o, 312 o, 357 p, 408 p

233 o, 311 o, 356, $413 \mathrm{p}$

233, 294, 336, 354

233, 294, 340, 345

233 o, 302 p, 360 p

230 o, 300 p, 368 o

$232,286,339$

$232,285,400$

233 o, 319 p, 354, $466 \mathrm{p}$

233 o, 316 p, 351, $462 \mathrm{p}$

$233,295,325,433$

233, 296, 327, 437

233 o, 308 o, 503 o, 570 p

232 o, 311 o, 346 o, 503 o, $571 \mathrm{p}$

$232,356,478$

232, 287, 346, 481

515 o, $599 \mathrm{p}, 705 \mathrm{p}$

516 o, $604 \mathrm{p}, 704 \mathrm{p}$

$515,590,678$

$515,594,700$

$377 \mathrm{o}, 431 \mathrm{p}, 463 \mathrm{p}$

377 o, $431 \mathrm{p}, 464 \mathrm{p}$

$371,378,457$

356,456

350 o, 506 p, 565 p, 600 p

311 o, 348, 506 o, 587 p, 603 p

$362,504,514$

$362,505,518$ 
Table 2 continued

Table 3 Heating and cooling features recorded during two temperature cycles with $1 \% \mathrm{~min}$ for sample of $X_{\mathrm{Ag}} / X_{\mathrm{Sb}}=1$

\begin{tabular}{|c|c|c|}
\hline Sample composition (sample no.) & Cycle (a) & $\begin{array}{l}\text { Thermal signals } \\
\text { Heating (b) and cooling (c) features, }{ }^{\circ} \mathrm{C}\end{array}$ \\
\hline \multirow[t]{4}{*}{$\mathrm{Ag}_{0.595} \mathrm{Sb}_{0.15} \mathrm{Sn}_{0.255}$ (s.16) } & h1 & 309 o, 355 o, 507 p, 544 p \\
\hline & h2 & 232 o, 312 о, 354 о 507 p, 541 p \\
\hline & $\mathrm{c} 1$ & $232,365,447$ \\
\hline & c2 & $230,359,425$ \\
\hline \multirow[t]{4}{*}{$\mathrm{Ag}_{0.49} \mathrm{Sb}_{0.3} \mathrm{Sn}_{0.21}$ (s.17) } & h1 & 376 o, $384 \mathrm{p}, 414 \mathrm{p}, 427 \mathrm{p}, 450 \mathrm{p}$ \\
\hline & h2 & 377 o, 384 p, 424 p, 481 p \\
\hline & $\mathrm{c} 1$ & 373,385 , \\
\hline & c2 & 371,382 \\
\hline \multirow[t]{4}{*}{$\mathrm{Ag}_{0.385} \mathrm{Sb}_{0.45} \mathrm{Sn}_{0.165}$ (s.18) } & h1 & 376 o, 449, $479 \mathrm{p}$ \\
\hline & h2 & 376 o, 435 p, 448 p, 478 p \\
\hline & $\mathrm{c} 1$ & $375,410,454$ \\
\hline & c2 & $372,383,455$ \\
\hline \multirow[t]{4}{*}{$\mathrm{Ag}_{0.24} \mathrm{Sb}_{0.2} \mathrm{Sn}_{0.56}$ (s.19) } & h1 & 233 o, 310, o, 335 p, 397 p \\
\hline & $\mathrm{h} 2$ & 233 o, 310 o, $334 \mathrm{p}, 405 \mathrm{p}$ \\
\hline & $\mathrm{c} 1$ & $232,291,317,364$ \\
\hline & c2 & $232,291,314,377$ \\
\hline \multirow[t]{4}{*}{$\mathrm{Ag}_{0.225} \mathrm{Sb}_{0.25} \mathrm{Sn}_{0.525}$ (s.20) } & h1 & 233 o, 310 o, $353 \mathrm{p}, 401 \mathrm{p}$ \\
\hline & $\mathrm{h} 2$ & 233 o, 311 o, 352 p, 399 p \\
\hline & $\mathrm{c} 1$ & $232,294,332,355$ \\
\hline & c2 & $232,295,335,357$ \\
\hline \multirow[t]{4}{*}{$\mathrm{Ag}_{0.23} \mathrm{Sb}_{0.25} \mathrm{Sn}_{0.52}$ (s.21) } & h1 & 233 o, 311 o, 338 p, 353 p, 398 p \\
\hline & h2 & 233 o, 310 o, 337 p, 352 p, 399 p \\
\hline & $\mathrm{c} 1$ & $232.5,295,332,355$ \\
\hline & $\mathrm{c} 2$ & $233,295,335,357$ \\
\hline
\end{tabular}

Symbol meaning: o-onset, $\mathrm{p}$ - peak

(a) h1, h2 and c1, c2-from first and second heating and cooling curves, respectively

(b) Onset for invariant reactions, peak maximum otherwise

(c) From endset

\begin{tabular}{lll}
\hline Sample composition (sample no.) & Cycle (a) & \multicolumn{1}{c}{$\begin{array}{c}\text { Thermal signals } \\
\text { Heating (b) and cooling (c) features, }{ }^{\circ} \mathrm{C}\end{array}$} \\
\hline $\mathrm{Ag}_{0.1} \mathrm{Sb}_{0.7} \mathrm{Sn}_{0.2}$ (s. 1) & $\mathrm{h} 1$ & $377 \mathrm{o}, 392 \mathrm{p}, 538 \mathrm{p}$ \\
& $\mathrm{c} 1$ & $355,366,514$ \\
$\mathrm{Ag}_{0.1} \mathrm{Sb}_{0.6} \mathrm{Sn}_{0.3}$ (s.2) & $\mathrm{h} 1$ & $377 \mathrm{o}, 382 \mathrm{p}$ \\
& $\mathrm{c} 1$ & 374,380 \\
$\mathrm{Ag}_{0.2} \mathrm{Sb}_{0.2} \mathrm{Sn}_{0.6}$ (s.5) & $\mathrm{h} 1$ & $234 \mathrm{o}, 309 \mathrm{o}, 328 \mathrm{p}, 374 \mathrm{o}, 386 \mathrm{p}$ \\
& $\mathrm{c} 1$ & $233,298,313,374$ \\
$\mathrm{Ag}_{0.25} \mathrm{Sb}_{0.25} \mathrm{Sn}_{0.5}$ (s.7) & $\mathrm{h} 1$ & $234 \mathrm{o}, 310 \mathrm{o}, 330 \mathrm{p}, 353 \mathrm{p}, 421 \mathrm{p}$ \\
& $\mathrm{h} 2$ & $234 \mathrm{o}, 310 \mathrm{o}, 330 \mathrm{p}, 354 \mathrm{p}, 423 \mathrm{p}$ \\
& $\mathrm{c} 1$ & $232,297,333$ \\
& $\mathrm{c} 2$ & $232,329,297,370$
\end{tabular}

Symbol meaning: o-onset, p-peak

(a) h1, h2 and c1, c2-from first and second heating and cooling curves, respectively

(b) Onset for invariant reactions, peak maximum otherwise

(c) From endset 
Table 4 Heating and cooling features recorded during two temperature cycles with $10 \%$ $\min$

\begin{tabular}{|c|c|c|}
\hline Sample composition (sample no.) & Cycle (a) & $\begin{array}{l}\text { Thermal signals } \\
\text { Heating (b) and cooling (c) features, }{ }^{\circ} \mathrm{C}\end{array}$ \\
\hline \multirow[t]{4}{*}{$\mathrm{Ag}_{0.1} \mathrm{Sb}_{0.7} \mathrm{Sn}_{0.2}$ (s. 1 ) } & h1 & $377 \mathrm{o}, 538 \mathrm{p}$ \\
\hline & h2 & 377 o, $536 \mathrm{p}$ \\
\hline & c1 & $356,366,506$ \\
\hline & c2 & $357,366,509$ \\
\hline \multirow[t]{4}{*}{$\mathrm{Ag}_{0.1} \mathrm{Sb}_{0.6} \mathrm{Sn}_{0.3}$ (s.2) } & h1 & 366 o, 376 o, $489 \mathrm{p}$ \\
\hline & h2 & 366 o, 376 o, $490 \mathrm{p}$ \\
\hline & $\mathrm{c} 1$ & $356,380,466$ \\
\hline & c2 & $357,380,476$ \\
\hline \multirow[t]{4}{*}{$\mathrm{Ag}_{0.2} \mathrm{Sb}_{0.6} \mathrm{Sn}_{0.2}(\mathrm{~s} .3)$} & h1 & $373 \mathrm{o}, 420 \mathrm{p}, 501 \mathrm{p}$ \\
\hline & h2 & $375 \mathrm{o}, 420 \mathrm{p}, 502 \mathrm{p}$ \\
\hline & $\mathrm{c} 1$ & 371,492 \\
\hline & c2 & $374.6,389,493$ \\
\hline \multirow[t]{4}{*}{$\mathrm{Ag}_{0.2} \mathrm{Sb}_{0.5} \mathrm{Sn}_{0.3}(\mathrm{~s} .4)$} & h1 & $367 \mathrm{o}, 453 \mathrm{p}, 467 \mathrm{p}$ \\
\hline & h2 & $372 \mathrm{o}, 455 \mathrm{p}, 467 \mathrm{p}$ \\
\hline & $\mathrm{c} 1$ & 360,444 \\
\hline & c2 & 359,444 \\
\hline \multirow[t]{2}{*}{$\mathrm{Ag}_{0.2} \mathrm{Sb}_{0.2} \mathrm{Sn}_{0.6}$ (s.5) } & h1 & 233 o, 311 o, 334 p, 386 p \\
\hline & $\mathrm{c} 1$ & $234,289,315,370$ \\
\hline \multirow[t]{2}{*}{$\mathrm{Ag}_{0.25} \mathrm{Sb}_{0.25} \mathrm{Sn}_{0.5}$ (s.7) } & h1 & 231 o, 312 o, $312 \mathrm{p}, 359 \mathrm{p}, 403 \mathrm{p}$ \\
\hline & $\mathrm{c} 1$ & $234,291,340,348$ \\
\hline \multirow[t]{4}{*}{$\mathrm{Ag}_{0.65} \mathrm{Sb}_{0.105} \mathrm{Sn}_{0.245}$ (s.11) } & h1 & 230.9 o, 311 o, 332 o, 503 o, $584 \mathrm{p}$ \\
\hline & h2 & 230.9 о, 311 o, 332 о, 503 о, 580.5 p \\
\hline & $\mathrm{c} 1$ & $234,290,346,474$ \\
\hline & $\mathrm{c} 2$ & $234,288,350,468$ \\
\hline
\end{tabular}

Symbol meaning: o-onset, $\mathrm{p}$ - peak

(a) h1, h2 and c1, c2-from first and second heating and cooling curves, respectively

(b) Onset for invariant reactions, peak maximum otherwise

(c) From endset

Table 5 Comparison of invariant reaction temperatures in Ag-Sb-Sn system obtained by experimental and assessment methods

\begin{tabular}{|c|c|c|c|c|c|c|c|c|}
\hline \multirow[t]{2}{*}{ Type of reaction } & \multirow[t]{2}{*}{ Invariant reactions } & \multicolumn{7}{|c|}{ Temperature, ${ }^{\circ} \mathrm{C}$} \\
\hline & & Ref 3 (a) & Ref 9 (b) & $\operatorname{Ref} 8$ (a) & Ref 10 (b) & Ref 11 (b) & Ref 12 (a) & This work (a) \\
\hline $\mathrm{U}_{1}$ & $\mathrm{~L}+(\mathrm{Sb}) \leftrightarrow \varepsilon+\mathrm{SbSn}$ & 378.5 & 375.0 & 379 & 388.1 & 379 & 375 & 376.5 \\
\hline $\mathrm{P}_{1}$ & $\mathrm{~L}+\varepsilon+\mathrm{SbSn} \leftrightarrow \mathrm{Sb}_{2} \mathrm{Sn}_{3}$ & $\ldots$ & 328.9 & $\ldots$ & $\ldots$ & $\ldots$ & $\ldots$ & $\ldots$ \\
\hline $\mathrm{U}_{2}$ & $\mathrm{~L}+\mathrm{Sb}_{2} \mathrm{Sn}_{3} \leftrightarrow \varepsilon+\beta-\mathrm{Sn}$ & & 231.6 & & & & $\cdots$ & $\ldots$ \\
\hline $\mathrm{U}_{2}$ & $\mathrm{~L}+\mathrm{SbSn} \leftrightarrow \varepsilon+\mathrm{Sb}_{2} \mathrm{Sn}_{3}$ & & $\ldots$ & 314 & 311.2 & 313.5 & 308 & 309.9 \\
\hline $\mathrm{U}_{3}$ & $\mathrm{~L}+\mathrm{Sb}_{2} \mathrm{Sn}_{3} \leftrightarrow \varepsilon+\beta-\mathrm{Sn}$ & 234.8 & & 233 & 231.4 & 231.5 & 229 & 231.8 \\
\hline $\mathrm{P}(?)$ & $\varepsilon+\mathrm{SbSn}+\beta-\mathrm{Sn} \leftrightarrow \mathrm{Sb}_{2} \mathrm{Sn}_{3}$ & $\ldots$ & $\ldots$ & $\ldots$ & & $\ldots$ & $<221$ & $\ldots$ \\
\hline
\end{tabular}
(a) Experimental
(b) Calculated

(samples 1-3, Table 6) or even third phase (sample 4, Table 6) in the $\varepsilon$ phase matrix was observed.

In a sample 4 (Table 6) three phases were detected after equilibration, which form the equilibrium of $(\mathrm{Sb})+\varepsilon+$ SbSn (Fig. 8b). Such three-phase field was suggested from results of experimental study of Lin et al. ${ }^{[6]}$ (samples: 17-21). It should be underlined that the existence of threephase equilibrium $(\mathrm{Sb})+\varepsilon+\mathrm{SbSn}$ in the $\mathrm{Ag}-\mathrm{Sb}-\mathrm{Sn}$ system was also suggested in the study of Masson and Kirkpatrick. ${ }^{[3]}$ 
The results obtained for sample 5 (Table 6) show the existence of two phase $\varepsilon+\mathrm{SbSn}$ equilibrium. This observation is compatible with the results of Lin et al. ${ }^{[6]}$ who after annealing Ag-Sb-Sn samples at $400{ }^{\circ} \mathrm{C}$ detected such two-phase field between two three-phase equilibria
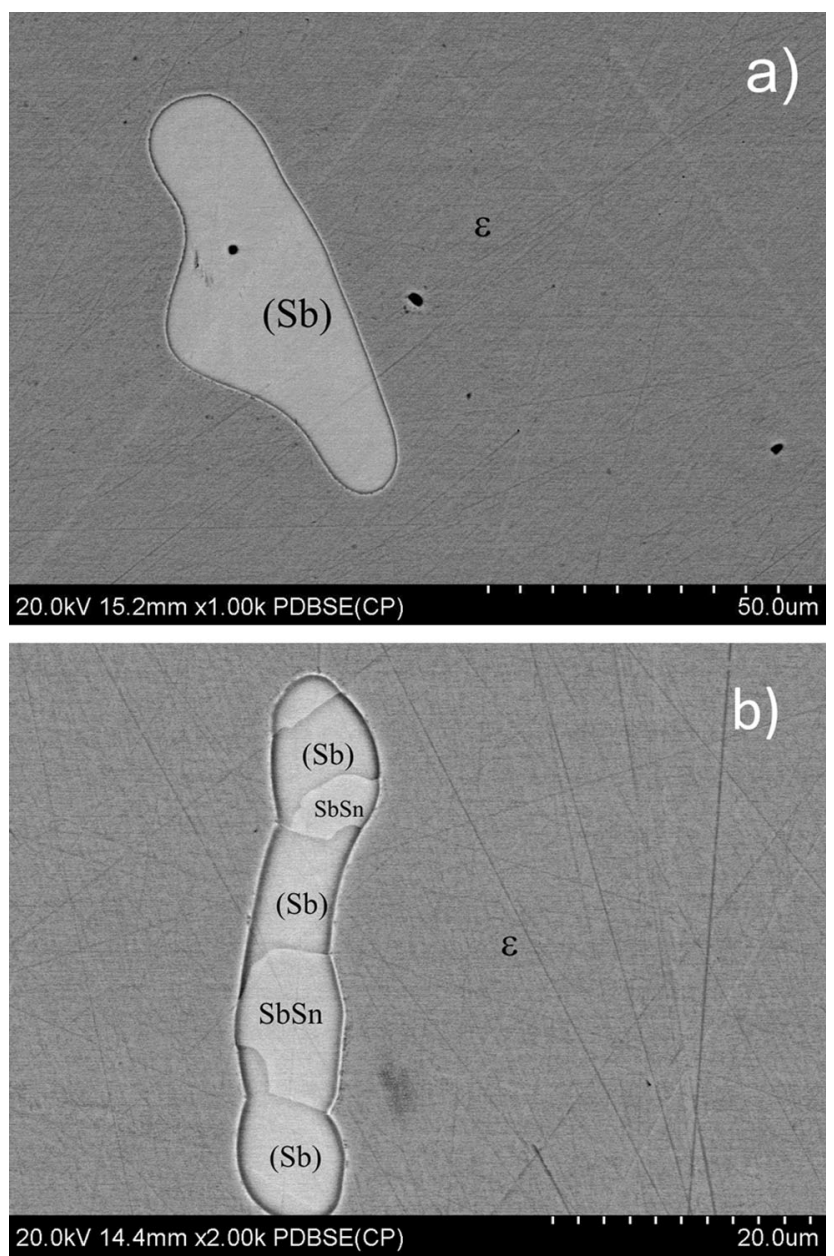

Fig. 8 BSE microphotographs of Ag-Sb-Sn samples equilibrated at $400{ }^{\circ} \mathrm{C}$ during 30 days. (a) Sample $0.74 \mathrm{Ag}-0.134 \mathrm{Sb}-0.126 \mathrm{Sn}$, (b) Sample $0.74 \mathrm{Ag}-0.082 \mathrm{Sb}-0.178 \mathrm{Sn}$. Black spots are holes
$(\mathrm{Sb})+\varepsilon+\mathrm{SbSn}$ and $\mathrm{SbSn}+\varepsilon+\mathrm{L}$, respectively. This topology does not agree with the ternary Ag-Sb-Sn diagram calculated at $400{ }^{\circ} \mathrm{C}$ from assessments of $\mathrm{Oh}$ et al., ${ }^{[9]}$ Moser et al. ${ }^{[10]}$ and Gierlotka et al., ${ }^{[11]}$ in which other ternary equilibrium $(\mathrm{Sb})+\mathrm{SbSn}+\mathrm{L}$ is present.

Again, it seems that the topological problems of the description of $\mathrm{Sb}-\mathrm{Sn}$ rich part of this ternary system will be solved after the proper explanation of phase equilibria in the binary tin-antimony system.

In case of the equilibration experiments conducted at $300{ }^{\circ} \mathrm{C}$ the applied time was not long enough to reach the phase equilibrium in studied samples. The component concentrations in the phase grains in the same sample polished section differ from one another in such way that it was not possible to choose the proper one. So these results were rejected.

\section{Conclusions}

A topological data of the ternary Ag-Sb-Sn system has been measured, involving:

- the DTA study of phase transition temperatures by the analysis of 19 different samples in the temperature range $100-850{ }^{\circ} \mathrm{C}$ during the 1,5 and $10 \%$ min heating and cooling cycles. The obtained results were compared with univariant and invariant temperatures calculated from available literature assessments of Ref 9-11 at the chosen phase diagram isopleth sections.

- the determination by SEM and EDX techniques of phase constituents and composition of coexisting phases of 5 samples after their thermal equilibration at $400{ }^{\circ} \mathrm{C}$.

New results obtained in this work can improve the optimization process of the ternary Ag-Sb-Sn system. Especially, our own experimental results can be used in the verification of the temperatures of invariant reactions and

Table 6 Results of equilibration at $400{ }^{\circ} \mathrm{C}$ of samples of fixed initial composition

\begin{tabular}{|c|c|c|c|c|c|c|c|c|c|}
\hline \multirow[t]{3}{*}{ Sample no } & \multicolumn{2}{|c|}{ Initial sample composition } & \multirow[t]{3}{*}{ Phases in equilibrium } & \multicolumn{6}{|c|}{ Composition of phases after equilibration } \\
\hline & \multirow[t]{2}{*}{$x_{\mathrm{Ag}}$} & \multirow[t]{2}{*}{$x_{\mathrm{Sb}}$} & & \multicolumn{2}{|c|}{ Phase 1} & \multicolumn{2}{|c|}{ Phase 2} & \multicolumn{2}{|c|}{ Phase 3} \\
\hline & & & & $x_{\mathrm{Ag}}$ & $x_{\mathrm{Sb}}$ & $x_{\mathrm{Ag}}$ & $x_{\mathrm{Sb}}$ & $x_{\mathrm{Ag}}$ & $x_{\mathrm{Sb}}$ \\
\hline 1 & 0.740 & 0.134 & $(\mathrm{Sb})+\varepsilon$ & 0.0 & 0.894 & 0.753 & 0.118 & $\ldots$ & $\cdots$ \\
\hline 2 & 0.742 & 0.173 & $(\mathrm{Sb})+\varepsilon$ & 0.0 & 0.904 & 0.750 & 0.171 & $\cdots$ & $\cdots$ \\
\hline 3 & 0.720 & 0.063 & $(\mathrm{Sb})+\varepsilon$ & 0.0 & 0.925 & 0.746 & 0.184 & $\cdots$ & $\ldots$ \\
\hline 4 & 0.740 & 0.082 & $(\mathrm{Sb})+\varepsilon+\mathrm{SbSn}$ & 0.0 & 0.870 & 0.748 & 0.078 & 0.002 & 0.607 \\
\hline 5 & 0.024 & 0.476 & $\varepsilon+\mathrm{SbSn}$ & 0.765 & 0.0 & 0.0 & 0.530 & $\ldots$ & $\ldots$ \\
\hline
\end{tabular}


univariant lines (liquidus, solidus or solvus) of the Ag-SbSn phase diagram.

Acknowledgments This work was supported by the State Committee for Scientific Research at AGH University Science and Technology, Faculty of Non-Ferrous Metals in Krakow, Poland under Grant No. 129/N-COST/2008.

Open Access This article is distributed under the terms of the Creative Commons Attribution 4.0 International License (http://crea tivecommons.org/licenses/by/4.0/), which permits unrestricted use, distribution, and reproduction in any medium, provided you give appropriate credit to the original author(s) and the source, provide a link to the Creative Commons license, and indicate if changes were made.

\section{References}

1. H.T. Lee, M.H. Chen, H.M. Jao, and C.J. Hsu, Effect of Adding $\mathrm{Sb}$ on Microstructure and Adhesive Strength of Sn-Ag Solder Joints, J. Electron. Mater., 2004, 33, p 1048-1054, in English

2. H.T. Lee, H.S. Lin, C.S. Lee, and P.W. Chen, Reliability of SnAg-Sb Lead-Free Solder Joints, Mater. Sci. Eng. A, 2005, 407, p 36-44, in English

3. D.B. Masson and B.K. Kirkpatrick, Equilibrium Solidification Solder Alloys of Sn-Ag-Sb Thermal Fatigue-Resistant, J. Electron. Mater., 1986, 15(6), p 350-353, in English

4. P.J.T.L. Oberndorff, A.A. Kodentsov, V. Vuorinen, J.K. Kivilahti, and F.J.J. van Loo, Phase Relations in the Sn-Ag-Sb System at $220{ }^{\circ} \mathrm{C}$, Ber. Bunsenges. Phys. Chem., 1998, 102(9), p 13211325, in English

5. R. Schmid-Fetzer, L. Rokhlin, E. Lysova, and M. Zinkevich, Silver-Antimony-Tin, Thermodynamic Properties Ternary Alloy Systems: Phase Diagrams, Crystallographic and Thermodynamic Data Critically Evaluated by MSIT, Noble Metal Systems. Selected Systems from Ag-Al-Zn to Rh-Ru-Sc, Vol 11B, G. Effenberg and S. Ilyenko, Ed., Springer, Berlin, 2006, p 181, in English
6. C.-Y. Lin, C. Lee, X. Liu, and Y.-W. Yen, Phase Equilibria of the $\mathrm{Sn}-\mathrm{Sb}-\mathrm{Ag}$ Ternary System and Interfacial Reactions at the $\mathrm{Sn}-\mathrm{Sb} /$ $\mathrm{Ag}$ Joints at $400{ }^{\circ} \mathrm{C}$ and $150{ }^{\circ} \mathrm{C}$, Intermetallics, 2008, 16(2), p 230-238, in English

7. C. Lee, C.-Y. Lin, and Y.-W. Yen, The $260{ }^{\circ} \mathrm{C}$ Phase Equilibria of the Sn-Sb-Ag Ternary System and Interfacial Reactions at the Sn-Sb/Ag Joints, J. Alloys Compd., 2008, 458, p 436-445, in English

8. S.-W. Chen, P.-Y. Chen, C.-N. Chiu, Y.-C. Huang, and C.-H. Wang, Phase Equilibria of the Sn-Sb-Ag Ternary System (I): Experimental, Metall. Mater. Trans. A, 2008, 39A(13), p 31913198, in English

9. C.S. Oh, J.H. Shim, B.J. Lee, and D.N. Lee, A thermodynamic study on the Ag-Sb-Sn system, J. Alloys Compd., 1996, 238, p 155-166, in English

10. Z. Moser, W. Gąsior, J. Pstruś, S. Ishihara, X.J. Liu, I. Ohnuma, R. Kainuma, and K. Ishida, Surface Tension and Density Measurements of $\mathrm{Sn}-\mathrm{Ag}-\mathrm{Sb}$ Liquid Alloys and Phase Diagram Calculations of the Sn-Ag-Sb ternary system, Mater. Trans., 2004, 45(3), p 652-660, in English

11. W. Gierlotka, Y.-C. Huang, and S.-W. Chen, Phase Equilibria of Sn-Sb-Ag Ternary System (II): Calculation, Metall. Mater. Trans. A, 2008, 39(13), p 3199-3209, in English

12. D. Li, S. Delsante, A. Watson, and G. Borzone, The Effect of Sb Addition on Sn-Based Alloys for High-Temperature Lead-Free Solders: An Investigation of the Ag-Sb-Sn System, J. Electron. Mater., 2012, 4(1), p 67-85, in English

13. C. Schmetterer, J. Polt, and H. Flandorfer, The Phase Equilibria in the Sb-Sn System-Part II: Experimental Results, J. Alloys Compd., 2018, 743(4), p 523-536, in English

14. J. Łapsa and B. Onderka, Thermodynamic Properties of Liquid Silver-Antimony-Tin Alloys Determined from Electrochemical and Calorimetric Measurements, J. Electron. Mater., 2016, 45(8), p 4441-4452, in English

15. B. Gather, P. Schröter, and R. Blachnik, Mixing Enthalpy of Ternary Systems Ag-In-Sn, Ag-Sn-Sb, Ag-In-Sb and In-Pb-Sb, Z. Metallkde., 1987, 78(4), p 280-285, in English

16. W.J. Boettinger, U.R. Kattner, K.-W. Moon, and J. Perepezko, DTA and Heat-flux DSC Measurements of Alloy Melting and Freezing, NIST Special Publication 960-15, 2006, in English 